\title{
Papers
}

\section{Spiritual beliefs may affect outcome of bereavement: prospective study}

\author{
Kiri Walsh, Michael King, Louise Jones, Adrian Tookman, Robert Blizard
}

\begin{abstract}
Objective To explore the relation between spiritual beliefs and resolution of bereavement.

Design Prospective cohort study of people about to be bereaved with follow up continuing for 14 months after the death.

Setting A Marie Curie centre for specialist palliative care in London.

Participants 135 relatives and close friends of patients admitted to the centre with terminal illness. Main outcome measure Core bereavement items, a standardised measure of grief, measured 1,9, and 14 months after the patients' death.

Results People reporting no spiritual belief had not resolved their grief by 14 months after the death. Participants with strong spiritual beliefs resolved their grief progressively over the same period. People with low levels of belief showed little change in the first nine months but thereafter resolved their grief. These differences approached significance in a repeated measures analysis of variance $(\mathrm{F}=2.42, \mathrm{P}=0.058)$. Strength of spiritual belief remained an important predictor after the explanatory power of relevant confounding variables was controlled for. At 14 months the difference between the group with no beliefs and the combined low and high belief groups was 7.30 (95\% confidence interval 0.86 to 13.73$)$ points on the core bereavement items scale. Adjusting for confounders in the final model reduced this difference to 4.64 (1.04 to 10.32) points.

Conclusion People who profess stronger spiritual beliefs seem to resolve their grief more rapidly and completely after the death of a close person than do people with no spiritual beliefs.
\end{abstract}

\section{Introduction}

Religious faith addresses the existential questions of life and death. Death of a close relative or companion is an extremely distressing experience, and grieving can take a long time. But little research on whether spiritual or religious beliefs alter the process of grief has been carried out. Studies of families coping with the death of a child ${ }^{12}$ and research into the adaptation of older people to widowhood ${ }^{3}$ suggest that religious belief affects the outcome of bereavement. Research is often retrospective, however, and causal connections are difficult to establish. ${ }^{1}$ Furthermore, research has been hampered by a lack of standardised measures. The development of valid and reliable measures of spiritual beliefs $^{4}$ and of the process of bereavement ${ }^{5}$ has enabled us to study the relation between spiritual beliefs and grieving. We aimed to test the null hypothesis that spiritual belief has no effect on the grieving process.

\section{Method}

Our prospective cohort study received approval from the local research ethics committee. All close relatives or friends of patients admitted between January 1997 and August 1998 to a Marie Curie centre for specialist palliative care in London were eligible to take part. Leaders from the main religions are on call for the centre 24 hours a day and a room is reserved for private thought and prayer. Patients are admitted from the local area, irrespective of their religious affiliation, and there is no manifest religious imagery or culture in the building. The centre has 32 beds for symptom control and respite, and continuing or terminal care. We consulted staff regarding the relative or friend thought to be closest to the patient and sought informed consent from these potential participants while they were at the centre. After giving their informed consent, participants underwent their first assessment.

We used standardised measures to assess strength of spiritual belief and bereavement outcome. We also hypothesised that age, sex, emotional status, cognitive style, and social networks could be associated with spiritual beliefs and bereavement outcome, thereby acting as confounders in the putative relation between them and included these likely confounders in our study. Participants completed five measures:

(1) The Royal Free interview for religious and spiritual beliefs assesses the nature and strength of spiritual beliefs and practice. ${ }^{4}$ It has high reliability and concurrent validity. A spiritual scale consists of questions in visual analogue format about the beliefs held. High scores indicate strongly held beliefs that play a major part in a person's life. Strength of spiritual belief is considered independently of religious observance.

(2) The core bereavement items scale measures the intensity of grief. It has high reliability and face and discriminant validity, and has been shown to be an important measure of change in grieving with time. ${ }^{5}$

(3) The hospital anxiety and depression scale $e^{6}$ is a brief measure of emotional status and is well validated.

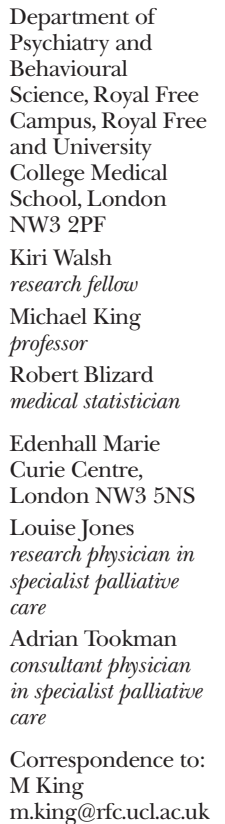

m.king@rfc.ucl.ac.uk

bmj.com 2002;324:1551 
(4) The close persons questionnaire measures social support. ${ }^{7}$ Participants are asked to nominate the people to whom they have felt closest and second closest during the preceding 12 months. A composite score of the frequency and number of contacts with relatives, friends, and social groups is also derived for the 12 month period. High scores indicate strong social ties.

(5) The locus of control of behaviour scale is a standardised measure of the extent to which people perceive events as being a consequence of their own behaviour and under personal control. ${ }^{8}$ Low scores indicate an internal locus of control and high scores indicate an external locus of control.

Although many people return to near normal four to six months after the death of a loved one, ${ }^{9}$ resolving a bereavement may take longer in others. Thus, we followed up participants at 1,9, and 14 months after the death of their relative or friend. We timed the final two assessments to avoid distress around the anniversary of the death. At each follow up we assessed the nature and intensity of grief by using the core bereavement items scale and asked participants to complete again the hospital anxiety and depression scale and the locus of control of behaviour scale.

\section{Data analysis}

We analysed the data using the statistics software package SPSS (versions 6 and 9). We used Student's $t$ test for normally distributed data and the $\chi^{2}$ statistic for categorical data. On an a priori basis, we divided the sample into three groups on the basis of their beliefs: no spiritual belief, low strength of belief, and high strength of belief. The latter two groups were divided on the mean score of the spiritual scale (the mean and median scores were 27). We compared the three groups by using analysis of variance and the Pearson $\chi^{2}$ statistic. We analysed our principal outcomes at 1,9 , and 14 months by using multivariate, repeated measures analyses. We present Greenhouse-Geisser adjusted $F$ ratios for the effect of time at 1,9 , and 14 months and the interaction of time and strength of belief to test whether the three strength of belief groups differed in their course of grief.

We conducted further exploratory analyses of the effects of the hypothesised confounders in the relation between spiritual belief and outcome of bereavement by using repeated measures, multivariate analyses of covariance in which age, depression, locus of control,

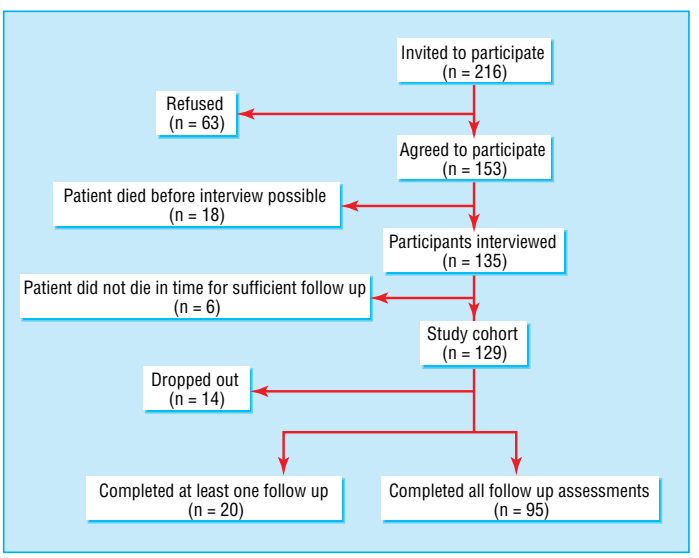

Fig 1 Flow chart for studying the effect of spiritual beliefs on outcome of bereavement

and degree of social isolation were included as covariates. Sex of the participant and emotional closeness to the patient were included as between subjects factors. We entered the covariates and factors into the analysis, beginning with demographic variables and following with psychological and then social variables. The final model included all variables that showed important $(\mathrm{P}<0.2)$ within subject or between subject effects. We retained strength of belief in the model because this addressed our main hypothesis.

We estimated that 170 participants would be sufficient to detect a moderate correlation of 0.25 between the scores on the core bereavement items scale and strength of spiritual beliefs with $90 \%$ power and at the $5 \%$ level of significance.

\section{Results}

\section{Response rates}

We approached 216 people, $153(71 \%)$ of whom agreed to be interviewed (fig 1). We found no significant difference in sex of people agreeing or refusing to take part. We did not undertake interviews with 18 participants because their relative or close friend died before the interview could be arranged. Therefore, a total of 135 people (90 women and 45 men) took part in the baseline interviews. In all, 129 patients $(96 \%)$ died within the time available for follow up and thus the relatives and friends of these $129 \mathrm{com}-$ prised the study cohort. Ninety five $(74 \%)$ of these

Table 1 Factors associated with response to follow up. Results are numbers (percentages) unless indicated otherwise

\begin{tabular}{|c|c|c|c|c|}
\hline \multirow[b]{2}{*}{ Variable } & \multicolumn{3}{|c|}{ No of follow ups completed } & \multirow[b]{2}{*}{ Significance } \\
\hline & None $(n=14)$ & At least one $(n=20)$ & All $(n=95)$ & \\
\hline Mean (SD) age & $49.5(19.4)^{\star}$ & $53.22(19.4)$ & $52.73(14.7) \dagger$ & $F=0.245, P=0.783$ \\
\hline Men & $7(50)$ & $7(35)$ & $31(33)$ & $\chi^{2}=1.62, P=0.445$ \\
\hline \multicolumn{5}{|l|}{ Relationship to deceased: } \\
\hline Spouse or partner & $6(43)$ & $7(35)$ & $38(40)$ & \multirow{3}{*}{$\chi^{2}=0.346, P=0.987$} \\
\hline Child & $5(36)$ & $9(45)$ & $38(40)$ & \\
\hline Other & $3(21)$ & $4(20)$ & $19(20)$ & \\
\hline \multicolumn{5}{|l|}{ Strength of spiritual belief: } \\
\hline High & $4(29)$ & $7(35)$ & $44(46)$ & \multirow{3}{*}{$\chi^{2}=6.34, P=0.175$} \\
\hline Low & $6(43)$ & $7(35)$ & $40(42)$ & \\
\hline None & $4(29)$ & $6(30)$ & $11(12)$ & \\
\hline $\begin{array}{l}\text { Mean (SD) hospital anxiety and } \\
\text { depression scale score }\end{array}$ & $20.00(8.5)$ & $15.05(9.5)$ & $18.58(7.9)$ & $F=1.89, P=0.155$ \\
\hline
\end{tabular}


Table 2 Characteristics of participants at entry to the study according to spiritual belief. Results are numbers (percentages) unless indicated otherwise

\begin{tabular}{|c|c|c|c|c|c|}
\hline \multirow[b]{2}{*}{ Characteristic } & \multicolumn{3}{|c|}{ Strength of spiritual belief } & \multirow{2}{*}{$\begin{array}{l}\text { All participants } \\
(n=129)\end{array}$} & \multirow[b]{2}{*}{ Significance } \\
\hline & None $(n=21)$ & Low $(n=53)$ & High $(n=55)$ & & \\
\hline Men & $12(57)$ & $17(32)$ & $16(29)$ & $45(35)$ & $\chi^{2}=5.6, P=0.062$ \\
\hline Mean (SD) age & $48(19.9)^{*}$ & $52(14.9) \dagger$ & $55(15) \dagger$ & $53(15.9)$ & $F=1.45, P=0.238$ \\
\hline Social class I, II, and IIIN & $14(67)$ & $32(60)$ & $37(67)$ & $83(64)$ & $\chi^{2}=0.62, P=0.734$ \\
\hline \multicolumn{6}{|l|}{ Relationship to dying patient: } \\
\hline Spouse or partner & $7(33)$ & $23(43)$ & $21(38)$ & $51(40)$ & $\chi^{2}=6.06, P=0.195$ \\
\hline Child & $10(48)$ & $24(45)$ & $18(33)$ & $52(40)$ & \\
\hline Other & $4(19)$ & $6(11)$ & $16(29)$ & $26(20)$ & \\
\hline Third level education & $6(29)$ & $11(21)$ & $19(35)$ & $36(28)$ & $\chi^{2}=2.56, P=0.278$ \\
\hline Married or cohabiting & $10(48)$ & $41(77)$ & $40(73)$ & $91(71)$ & $\chi^{2}=6.62, \mathrm{P}=0.036$ \\
\hline White ethnic group & $18(86)$ & $52(98)$ & $47(85)$ & 117 (91) & $\chi^{2}=5.86, P=0.053$ \\
\hline Mean (SD) HADS & $18.6(8.0)$ & $18.8(8.1)$ & $17.4(8.7)$ & $18.2(8.3)$ & $F=0.409, P=0.665$ \\
\hline Mean (SD) locus of control & $30.1(10.4)$ & $30.7(11.1) \ddagger$ & $32.4(9.7)$ & $31.4(10.4) \S$ & $F=0.532, P=0.589$ \\
\hline
\end{tabular}

HADS=hospital anxiety and depression scale.

${ }^{*}$ Data missing for one person.

†Data missing for two people.

$\ddagger \mathrm{n}=51$.

$\S n=127$.

completed all follow up assessments. No significant differences were found between non-responders, responders with incomplete data, and those who completed all assessments (table 1), although there was a tendency for people with no spiritual beliefs to fail to complete all follow ups.

\section{Baseline characteristics}

Fifty one participants (40\%) were the spouse or partner of the dying patient and $52(40 \%)$ were their adult children. The remaining $26(20 \%)$ were made up of $9(7 \%)$ friends and $17(13 \%)$ other relatives. Fifty two (40\%) named the dying patient as the person they had felt closest to over the previous 12 months, with a further $13(10 \%)$ naming the dying patient as the second closest person to them. Of the 114 patients for whom data were not available, the mean age at death was 67 years (SD 12.3, range 28-94); only eight (7\%) of the people whose age was known were under 50 . In all, 72/129 $(56 \%)$ patients died within one month of the baseline interview with their participating friend or relative, a further $37(29 \%)$ died within three months, and 20 (16\%) died more than three months later. At first follow up one month after the death, participants were asked about the circumstances of the death. Of the 114 who were asked, $65(57 \%)$ were present at the death, whereas $88(77 \%)$ had wanted to be there. Thirty-nine $(80 \%)$ of those who were not present at the death had seen the patient in the preceding 24 hours. These findings indicate that we had been successful in recruiting people who were closely involved with the dying patient.

A total of $21 / 129$ people $(16 \%)$ reported no religious or spiritual belief; 53 (41\% of all participants) reported spiritual beliefs of low intensity and $55(43 \%)$ reported strongly held beliefs (table 2). Marital status and ethnic origin were significantly related to spiritual

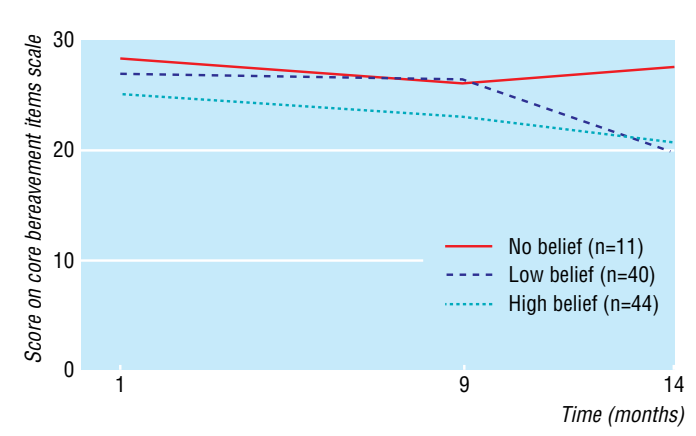

Fig 2 Strength of spiritual belief and outcome of bereavement

belief: people with partners had stronger beliefs, and almost everyone in the low belief group was white.

\section{Spiritual belief and outcome of bereavement}

The main result of this study arose from the analysis of the 95 participants $(74 \%)$ who completed all follow up assessments (table 3). Participants with strongly held spiritual beliefs recovered from their bereavement in a linear fashion (fig 2), whereas those with low strength of belief showed little change by nine months but recovered rapidly thereafter. Participants with no spiritual beliefs showed a temporary gain at nine months but their symptoms of grief had intensified again by the final assessment.

To explore the potential effect of confounders on the main outcomes, our first multivariate analysis concerned the 95 people who completed all assessments. The first line of table 4 describes the effects of time and the interaction between time and strength of belief, when strength of belief is the only variable entered into the model. We found a borderline significant effect

Table 3 Outcome of bereavement for participants who completed the study, for each spiritual belief category, using the core bereavement items scale

\begin{tabular}{|c|c|c|c|c|}
\hline \multirow{2}{*}{$\begin{array}{l}\text { Mean core bereavement } \\
\text { items }(95 \% \mathrm{Cl})\end{array}$} & \multicolumn{3}{|c|}{ Strength of spiritual belief } & \multirow[b]{2}{*}{ All participants $(n=95)$} \\
\hline & None $(n=11)$ & Low $(n=40)$ & High $(n=44)$ & \\
\hline 1 month & 28.62 (24.0 to 33.3$)$ & 27.03 (22.9 to 31.2) & 25.37 (22.2 to 28.6) & 26.44 (24.1 to 28.7$)$ \\
\hline 9 months & 26.00 (20.6 to 31.4 ) & 26.36 (22.6 to 30.1$)$ & 22.98 (19.8 to 26.2) & 24.76 (22.5 to 27.0 ) \\
\hline 14 months & 27.53 (22.3 to 32.8$)$ & 19.82 (16.6 to 23.1) & 20.61 (17.4 to 23.9) & 21.08 (19.0 to 23.2) \\
\hline
\end{tabular}


Table 4 Repeated measures analysis of spiritual belief and bereavement outcome showing the effects of covariate adjustments ( $n=95)$

\begin{tabular}{|c|c|c|c|c|c|c|}
\hline \multirow[b]{2}{*}{ Variables in model } & \multicolumn{4}{|c|}{ Greenhouse-Geisser $\mathrm{F}$ ratio } & \multicolumn{2}{|c|}{ Other effects } \\
\hline & Time & $P$ value & Time by strength & P value & Variable & Significance \\
\hline Time plus strength of spiritual belief & 7.93 & 0.001 & 2.42 & 0.058 & & \\
\hline Plus sex and age & 9.98 & $<0.001$ & 2.55 & 0.050 & Sex-time interaction & $F=3.56, P=0.037$ \\
\hline \multirow{2}{*}{$\begin{array}{l}\text { Plus mean HADS and locus of } \\
\text { control scale score }\end{array}$} & \multirow[t]{2}{*}{9.67} & \multirow[t]{2}{*}{$<0.001$} & \multirow[t]{2}{*}{2.37} & \multirow[t]{2}{*}{0.063} & Mean HADS score & $t=4.9, P<0.001$ \\
\hline & & & & & Sex-time interaction & $F=3.73, P=0.032$ \\
\hline \multirow{3}{*}{$\begin{array}{l}\text { Plus total isolation score* and } \\
\text { closeness to patient* }\end{array}$} & \multirow[t]{3}{*}{4.82} & \multirow[t]{3}{*}{0.013} & \multirow[t]{3}{*}{1.34} & \multirow[t]{3}{*}{0.263} & Closeness to patient ${ }^{*}$ & $F=9.18, P=0.003$ \\
\hline & & & & & Mean HADS score & $t=4.4, P<0.001$ \\
\hline & & & & & Sex-time interaction & $F=2.88, P=0.067$ \\
\hline \multirow{3}{*}{$\begin{array}{l}\text { Final model: strength of spiritual } \\
\text { belief, sex, closeness to patient }{ }^{\star} \text {, } \\
\text { with HADS }\end{array}$} & \multirow[t]{3}{*}{5.75} & \multirow[t]{3}{*}{0.006} & \multirow[t]{3}{*}{2.11} & \multirow[t]{3}{*}{0.091} & Closeness to patient* & $F=11.8, P=0.001$ \\
\hline & & & & & Mean HADS score & $t=5.3, P<0.001$ \\
\hline & & & & & Sex-time interaction & $F=3.3, P=0.047$ \\
\hline
\end{tabular}

HADS=hospital anxiety and depression scale.

${ }^{*}$ From close persons questionnaire.

$(\mathrm{P}=0.058)$ for the interaction between strength of belief and time (fig 2).

We then examined three groups of potential confounders of the relation between spiritual belief and outcome of bereavement. When we entered the demographic variables of sex and age into the model, the effect of strength of belief remained significant (table 4). Although sex of the participant was important (men had higher grief scores than women initially but not by nine months), it did not remove the effect of strength of belief on the course of grieving. Age was not a significant covariate in initial grief or recovery with time. We then examined the effects of psychological status and locus of control. Mean scores on the hospital anxiety and depression scale before the death were significantly associated with initial levels of grief. Higher depression scores at baseline also predicted higher scores on the core bereavement items scale at all follow ups. However, scores on the hospital anxiety and depression scale or mean locus of control scale failed to have a major impact on the effect of strength of belief $(\mathrm{P}=0.063)$ or the interaction between sex and time. Next, we examined the effects of social isolation and emotional closeness of the participant to the deceased. Adding these variables reduced the effect of strength of belief $(\mathrm{P}=0.263)$. Closeness to the dying patient predicted higher grief scores at all follow ups. The final model included strength of belief, sex, and closeness to the deceased as between subject factors and hospital anxiety and depression scale score at baseline as a covariate. Strength of spiritual belief retained its borderline significance. At 14 months the difference between the group with no beliefs and the combined low and high belief groups was 7.30 (95\% confidence interval 0.86 to 13.73 ) points on the core bereavement items scale. Adjusting for confounders in the final model (table 4) reduced this difference to 4.64 (1.04 to 10.32) points. These figures correspond to an effect size of 0.65 standard deviations before adjustment for confounding and 0.41 standard deviations after adjustment.

We undertook the same analysis, using all 114 people who had completed the baseline and first follow up assessments, imputing missing values thereafter by using the last observation carried forward. The interaction between time and strength of belief was confirmed $(\mathrm{P}=0.034)$ (table 5). Results for the whole model were similar using this larger sample, with strength of belief remaining significant $(\mathrm{P}=0.021)$ when all significant covariates and factors of interest were included.

\section{Discussion}

In recent years research has moved from focusing on the psychological and medical consequences of grieving to examining what constitutes vulnerability and resilience in bereavement. Our main finding is that strength of spiritual belief is an important predictor of bereavement outcome. People with low strength of belief resolved their grief more slowly during the first nine months but by 14 months had caught up with people with strong beliefs. Participants with no spiritual beliefs had higher grief scores than the remainder at the one month and 14 month follow up points. The comparison fell short of statistical

Table 5 Repeated measures analysis of spiritual belief and bereavement outcome showing the effects of covariate adjustments $(\mathrm{n}=114$; imputed data using last observation carried forward)

\begin{tabular}{|c|c|c|c|c|c|c|}
\hline \multirow[b]{2}{*}{ Variables in model } & \multicolumn{4}{|c|}{ Greenhouse-Geisser F ratio } & \multicolumn{2}{|c|}{ Other effects } \\
\hline & Time & $P$ value & Time by strength & $P$ value & Variable & Significance \\
\hline $\begin{array}{l}\text { Time plus strength of spiritual } \\
\text { belief }\end{array}$ & 10.99 & $<0.001$ & 2.78 & 0.034 & & \\
\hline Plus sex and age & 14.02 & $<0.001$ & 3.23 & 0.018 & Sex-time interaction & $F=4.06, P=0.023$ \\
\hline \multirow{2}{*}{$\begin{array}{l}\text { Plus mean HADS and locus of } \\
\text { control scale score }\end{array}$} & \multirow[t]{2}{*}{13.44} & \multirow[t]{2}{*}{$<0.001$} & \multirow[t]{2}{*}{2.94} & \multirow[t]{2}{*}{0.026} & Mean HADS score & $t=5.2, P<0.001$ \\
\hline & & & & & Sex-time interaction & $F=4.26, P=0.019$ \\
\hline \multirow{3}{*}{$\begin{array}{l}\text { Plus total isolation score }{ }^{*} \text { and } \\
\text { closeness to patient }\end{array}$} & \multirow[t]{3}{*}{5.26} & \multirow[t]{3}{*}{0.008} & \multirow[t]{3}{*}{2.06} & \multirow[t]{3}{*}{0.097} & Closeness to patient ${ }^{\star}$ & $F=8.65, P=0.004$ \\
\hline & & & & & Mean HADS score & $t=4.3, P<0.001$ \\
\hline & & & & & Sex-time interaction & $F=3.29, P=0.046$ \\
\hline \multirow{3}{*}{$\begin{array}{l}\text { Final model: strength of spiritual } \\
\text { belief, sex, closeness to patient*, } \\
\text { with HADS }\end{array}$} & \multirow[t]{3}{*}{6.48} & \multirow[t]{3}{*}{0.003} & \multirow[t]{3}{*}{3.13} & \multirow[t]{3}{*}{0.021} & Closeness to patient ${ }^{*}$ & $F=12.3, P=0.001$ \\
\hline & & & & & Mean HADS score & $t=5.7, P<0.001$ \\
\hline & & & & & Sex-time interaction & $F=3.8, P=0.029$ \\
\hline
\end{tabular}

HADS=hospital anxiety and depression scale.

${ }^{\star}$ From close persons questionnaire. 
significance, but strength of spiritual belief remained an important predictor after the explanatory power of most other variables was controlled for. Although the degree of closeness to the person who died and the level of emotional distress before the death increased feelings of grief, neither affected the rate at which the grief was resolved.

\section{Limitations of the study}

One limitation of our study is sample size, which restricts the number of potential confounders we can explore. Set against that is the difficulty of recruiting a large sample of people before the death of their loved one and following them for a considerable time afterwards. Another limitation is a lack of qualitative detail to help in our interpretation of the results. It would also have been useful to know more about participants' experiences of palliative care and counselling before the death. However, to avoid overburdening the participants, we restricted ourselves to data that were germane to our hypothesis.

Great sensitivity was required in approaching participants, and it was inevitable that a proportion would refuse to participate. This may simply have been because they moved address. But we cannot know whether some dropped out because of unresolved bereavement issues or dissatisfaction with the circumstances of the death.

\section{Strengths of the study}

The strengths of our study are that it was prospective over a long follow up period and that we recruited participants in a secular palliative care unit that has no religious affiliation. A further strength is that we recruited participants before they were bereaved. Most participants, however, appreciated that their loved one was very sick and that their death was imminent. Furthermore, not all participants completed all follow ups.

\section{Spiritual belief}

Spiritual beliefs may provide an existential framework in which grief is resolved more readily. Most spiritual beliefs, whether or not associated with religious practice, contain tenets about the course of human life and existence beyond it. Strong beliefs may be a proxy for better adjustment and less psychological distress. But our analysis suggests that strength of belief affected the course of bereavement, independently of psychological status. Relating to a person with terminal illness may sharpen our focus on spiritual or existential matters. Participants in this cohort, however, held beliefs that were similar in character and strength to those of other populations in which this standardised measure of spiritual and religious beliefs has been used. ${ }^{1011}$

\section{Concluding remarks}

If our results were replicated, this would show that the absence of spiritual belief is a risk factor for delayed or complicated grief. It has been thought that sensitive discussions between palliative care staff and relatives before a death have a positive impact on subsequent bereavement. ${ }^{12}$ Most palliative care units try to involve family members and friends who are important and close to the person dying. Attention to spiritual matters

\section{What is already known on this topic}

Religious belief affects outcome of bereavement in families coping with the death of a child and in older people who are bereaved of a spouse

Research is often retrospective, and causal connections are difficult to establish

\section{What this study adds}

People who profess stronger spiritual beliefs seem to resolve their grief more rapidly and completely after the death of a person close to them than do people with no spiritual beliefs

Most palliative care units involve the family members and friends of the person dying; attention to spiritual matters may be an important component of this work

may be a component in this work that is often overlooked or avoided by secular services. We are not suggesting that an intervention concerning spiritual matters is appropriate for people with no professed beliefs. Rather, our finding might help in identifying people who are having difficulty in readjusting to life after their loss.

We thank all participants and the Marie Curie staff who made the study possible. We acknowledge the contributions of Pippa Winton and Evelyn Blumenthal-counsellors at the Edenhall Marie Curie Centre--who provided valuable emotional support to KW.

Funding: Leverhulme Trust.

Contributors: MK, AT, and LJ conceived the idea for the study and obtained research funding. MK, LJ, and AT supervised the conduct of the study and data collection. KW recruited participants and collected data. KW, RB, and MK analysed the data. All authors contributed to the writing of the paper. MK is the guarantor for the study.

Competing interests: None declared.

1 Lauer ME, Mulhern RK, Schell MJ, Camitta BM. Long term follow-up of parental adjustment following a child's death at home or hospital. Cancer 1989;63:988-94.

2 McIntosh DN, Silver RC, Wortman CB. Religion's role in adjustment to a negative life event: coping with the loss of a child. J Pers Soc Psychol 1993;65:812-21.

3 Rosik CH. The impact of religious orientation in conjugal bereavement among older adults. Int J Aging Hum Dev 1989;28:251-60.

4 King M, Speck P, Thomas A. The Royal Free interview for religious and spiritual beliefs: development and standardisation. Psychol Med 1995;25:1125-34

5 Burnett P, Middleton W, Raphael B, Martinek N. Measuring core bereavement phenomena. Psychol Med 1997;27:49-57.

6 Zigmond AS, Snaith RP. The hospital anxiety and depression scale. Acta Psychiatr Scand 1983;67:361-70.

7 Stansfeld S, Marmot M. Deriving a survey measure of social support: the reliability and validity of the close persons questionnaire. Soc Sci Med 1992;35:1027-35

8 Craig AR, Franklin JA, Andrews G. A scale to measure locus of control of behaviour. BrJ Med Psychol 1984;57:173-80.

9 Clayton PJ. Bereavement and depression. J Clin Psychiatry 1990;51(suppl):34-40.

10 King M, Speck P, Thomas A. The effect of spiritual beliefs on outcome from illness. Soc Sci Med 1999;48:1291-9.

11 King M, Speck P, Thomas A. The Royal Free interview for spiritual and religious beliefs: development and validation of an expanded, self-report version. Psychol Med 2001;31:1015-23.

12 Huber R, Gibson JW. New evidence for anticipatory grief. Hosp J 1990;6:49-67.

(Accepted 2 January 2002) 